\title{
PHYSICAL PROPERTIES AND STRUCTURE OF VAPOR-QUENCHED
} IMMISCIBLE ALLOYS

\author{
V. F. Bashev, N. A. Kutseva, O. I. Kushnerov, S. I. Ryabtsev", S. N. Antropov \\ Oles Honchar Dnipro National University, Dnipro, Ukraine \\ *e-mail: siryabts@gmail.com
}

\begin{abstract}
The method of modernized ion-plasma sputtering produced metastable states, including nanocrystalline and amorphous phases in films of Fe-Ag, Fe-Bi, Fe-Ag-Bi, Fe-Co-Ag and Ni-Ag alloys whose components do not mixed in the liquid state. The periods of the crystal lattices and the dimensions of the crystallites of the nonequilibrium phases in the fresh-sputtered state and after the heating are determined. The temperatures of the beginning and the end of the decomposition of metastable phases are established when heated at a constant rate. The electric and hysteretic magnetic properties of films in freshly dusted and thermally processed states are measured. The compositions and conditions for obtaining films with low values of the temperature coefficient of electrical resistivity $\left(\sim 10^{-5} \mathrm{~K}^{-1}\right)$ and high coercive force $\left(\mathrm{H}_{\mathrm{C}} \sim 150 \mathrm{kA} / \mathrm{m}\right)$ are established. Such films can be promising for use as thin-film precision resistors and magnetic information carriers with an increased recording density.
\end{abstract}

Keywords: quenching from the vapor state, ion-plasma sputtering, immiscible alloys, nanocrystalline structure, amorphous phases, properties

Received 20.09.2018; Received in revised form 12.10.2018; Accepted 10.11.2018

\section{Introduction}

Interest in materials based on components with a very limited mutual solubility in the liquid state has recently increased significantly [1-2]. The peculiarities of such systems include: a large difference in the specific gravity of the components, the presence of a monotectic transformation, a tendency to exfoliation in the liquid state in a wide temperatureconcentration interval, which unambiguously indicates a high positive heat of mixing of the alloy components. These factors significantly complicate the use of immiscible components in industry and high technology. However, the application of extremely nonequilibrium conditions for obtaining or processing a material allows us to overcome the effects of positive enthalpy of mixing and to obtain a new class of promising materials. It is also known that the quenching process from a liquid state with cooling rates of $10^{6}-10^{8} \mathrm{~K} / \mathrm{s}$ is accompanied by the appearance of high internal pressures, often leading to the formation of high-pressure phases [3]. The effective rate of energy relaxation at different modes of precipitation is theoretically estimated to be $10^{12}-10^{14} \mathrm{~K} / \mathrm{s}$ when ion-plasma sputtering of atoms. This makes it possible to speak of quenching from the vapor state and opens the possibility of the appearance of high-pressure phases even during ion-plasma sputtering. All this and a many of immiscible systems (about 200 systems of metal-metal type) determine the relevance and prospects of research of a new class of materials for the industry. To date, sufficiently many single-phase alloys have already been obtained in systems of immiscible components characterized by anomalously large positive mixing energy by different methods, primarily quenching from the vapor phase, amorphous phases and highly supersaturated solid solutions [4-8].

The purpose of this work was to determine the effect of the extremely high cooling rates achieved in the modernized ion-plasma sputtering method [9] on the features of phase formation of alloys $(\mathrm{Ni}, \mathrm{Fe}, \mathrm{Co})$ - (Ag, Bi), whose components practically do not mix even in the liquid state, and their electrical and magnetic properties.

\section{Materials and methods}

It is known that in systems with positive mixing energy, the energy barriers for the formation of homogeneous structures are rather high [10]. To overcome them, it is necessary 
that the kinetic energy of the atoms that fall on the substrate exceed the height of these barriers. According to the calculated estimates given in [11], the mixing energy values for Ag-Fe alloys are $94 \mathrm{~kJ} / \mathrm{mol}, \mathrm{Fe}-\mathrm{Bi}-80 \mathrm{~kJ} / \mathrm{mol}, \mathrm{Co}-\mathrm{Ag}-63 \mathrm{~kJ} / \mathrm{mol}, \mathrm{Ni}-\mathrm{Ag}-52 \mathrm{~kJ} / \mathrm{mol}$. Therefore, the production of films was carried out using the method of three-electrode modernized ion-plasma sputtering (MIPS) of reticulated targets [9]. The targets were parallelepipeds of pure (not less than $99.99 \%$ ) elements $20 \times 20 \mathrm{~mm}$ in size and $5 \mathrm{~mm}$ in height separated by barrier cells with the function of electrostatic lenses. This allows, in comparison with conventional three-electrode ion-plasma sputtering, to increase the energy of atoms atomized from the target 5-7 times before colliding with the substrate on which deposition was carried out. It was shown that the kinetic energy of the deposited atoms using the MIPS method can vary from 100 to $200 \mathrm{eV}$ with a decrease in the pressure of the plasma-forming gas from 53 to $16 \mathrm{mPa}$ [12]. The rate of relaxation of the energy of the deposited atoms under different spraying regimes is theoretically estimated to be $10^{12}-10^{14} \mathrm{~K} / \mathrm{s}$ [13], which is $7-8$ orders of magnitude higher than the maximum cooling rates that are realized during the quenching from the liquid state (QLS). This allows us to talk about quenching from the vapor state (QVS).

Sputtering was carried out on the glassceramic substrates, as well as on a fresh cleavage of $\mathrm{NaCl}$ single crystal. To evaluate the compositions of the resulting films, a technique was used [9], which considered the relationship between the relative sputtering area the element occupies and its content in the deposited film. This technique makes it possible to determine the film composition to within \pm 0.5 at.\%. The thickness of the films was varied by the deposition time in the range $0.02-2.9 \mu \mathrm{m}$.

Films deposited on $\mathrm{NaCl}$ single crystal substrates after dissolving the salt were used for structural studies by electron microscopy for transmission and X-ray diffraction analysis in filtered cobalt $\mathrm{K}_{\alpha}$-radiation. Films obtained under identical sputtering conditions on the glassceramic substrates were used to investigate the physical properties of nonequilibrium structures. Measurements of the change in the electrical resistivity of the films upon heating were carried out in a vacuum of $\sim 13.3 \mathrm{mPa}$ by a four-probe method. Measurements of the coercive force $\mathrm{H}_{\mathrm{C}}$ of films were carried out on a vibrating magnetometer in a maximum magnetizing field of $0.5 \mathrm{~T}$ applied parallel and perpendicular to the surface of the films.

The objects of investigation in the present paper were films of alloys of the following compositions: Ni- (21- 88) at.\% Ag; Fe- (12-49) at.\% Ag, Fe- (5-18) at.\% Bi; Co-(24-28) at.\% Fe-(7-20) at.\% Ag; Fe-(11.5-21) at.\% Ag-(4-4.5) at.\% Bi. Equilibrium phase diagrams of the investigated binary systems Ni-Ag, Fe-Ag, Fe-Bi, Co-Ag are characterized by extremely low mutual solubility of the components even at eutectic temperatures and the presence of wide temperature-concentration separation intervals in the liquid state [14].

\section{Results and their discussion}

The solubility of $\mathrm{Ag}$ in $\mathrm{Ni}$ and $\mathrm{Ni}$ in $\mathrm{Ag}$ at $1708 \mathrm{~K}$ does not exceed $~ 5$ at.\% [14]. $\mathrm{Ni}$-Ag films have been investigated in more detail, since this system has been the object of numerous experimental studies and modeling [1]. This allows us to consider it as a model for assessing the effectiveness of the MIPS method.

In freshly deposited $\mathrm{Ni}-\mathrm{Ag}$ films with a content of $(0-21)$ at.\% $\mathrm{Ag}$, the X-ray patterns show predominantly Ni lines. In the Ag-Ni films and with the content and (42100) at.\% Ag, Ag lines were fixed. Calculations of the periods of fcc Ni and Ag lattices have shown that in these concentration intervals, supersaturated solid solutions form in 
the films, the saturation of which increases with increasing doping level (Fig. 1). Diffraction patterns of Ni- (21-42) at.\% Ag films contained a diffuse halo. The presence of such a halo indicates the formation of an amorphous phase. The dimensions of the coherent scattering regions for films of this composition are $\sim 1.6 \mathrm{~nm}$, which is characteristic of metal alloys with an amorphous structure.

It should be noted that an amorphous structure was observed in Ni- (20-60) at.\% Ag films prepared by magnetron sputtering by the authors [1]. In these studies, by the methods of high-resolution transmission electron microscopy in combination with simulation results showed that the films have a truly amorphous structure, although heterogeneous on an atomic scale. This heterogeneity consists in the presence of nanoscale clusters consisting mainly of like atoms, and its external manifestation is the complex form of the diffraction maximum.

The presence in the film structure of the nanocrystalline phase is indicated by the presence on the X-ray diffraction patterns of the first line with the effective size of the coherent scattering regions $(\mathrm{CSR}) \mathrm{L}=2-12 \mathrm{~nm}$. The size of the regions was estimated by the Selyakov-Scherer formula. The fixed interplanar distance makes it possible to assume that the short-range order in the arrangement of atoms in the microcrystalline phase is close to the bcc orientation of iron-based atoms.

In the films of Fe-Ag binary alloys with a positive mixing energy of $\sim 94 \mathrm{~kJ} / \mathrm{mol}$, a mixture of two solid solutions based on the components was formed. The average size of these structural components tended to decrease with increasing Ag concentration. The size of a-Fe crystals decreased from 200 to $9 \mathrm{~nm}$, and $\mathrm{Ag}$ - to $18 \mathrm{~nm}$. It should be noted that an analogous phase composition (a mixture of nanoscale crystallites of two solid solutions) had $0.2 \mu \mathrm{m}$ thick Ag-Fe films obtained by magnetron sputtering [4]. A typical $\mathrm{X}$-ray diffraction pattern of a freshly deposited film after photometry is shown in Fig. 2.

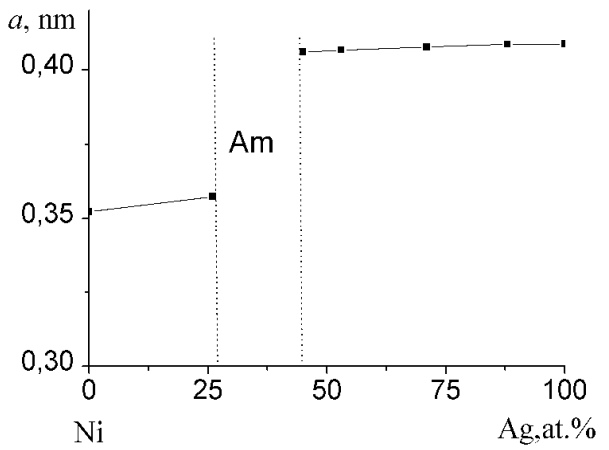

Fig. 1. Concentration dependence of the lattice parameter of as-deposited Ni-Ag films

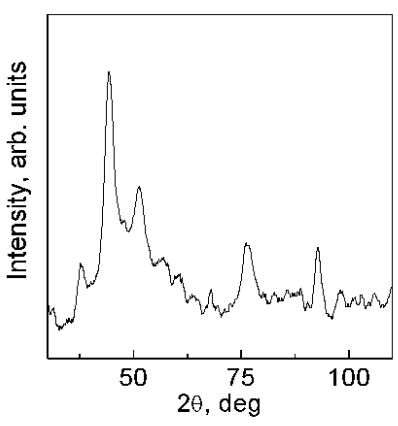

Fig. 2. X-ray diffraction pattern of the asdeposited $\mathrm{Fe}_{51} \mathrm{Ag}_{49}$ film.

The Fe-Bi system also belongs to the class of systems with immiscible elements in the liquid state and is characterized by a high $(\sim 80 \mathrm{~kJ} / \mathrm{mol})$ positive mixing energy. A somewhat unexpected result was obtained when studying the structure of sputtered films of $\mathrm{Fe}-(5-18)$ at.\% Bi alloys. As the concentration of $\mathrm{Bi}$ was increased to 18 at.\%, The size of the CSR of $\alpha$-Fe decreased to $6 \mathrm{~nm}$, and additional weak reflections appeared in the diffraction patterns of the films, the angular position of which corresponded to the bcc phase with a period of $0.378 \pm 0.001 \mathrm{~nm}$. The formation of a similar phase was observed earlier at elevated pressures $(a=0.3795 \mathrm{~nm})$ [15]. To clarify the phase composition of the Fe-Bi films, a pure Bi film with a thickness of $\sim 2900 \mathrm{~nm}$ was obtained. An analysis of the x-ray pattern of this film showed that, in addition to the diffuse lines of rhombohedral 
$\mathrm{Bi}$, it contains reflections of the bcc phase with a period of $0.379 \mathrm{~nm}$. The thermal treatment of the films (heating to a temperature of $613 \mathrm{~K}$ ) leads to the disappearance of the bcc phase lines, which indicates its metastable nature.

In films of $\mathrm{Co}-28 \% \mathrm{Fe}-7 \% \mathrm{Ag}$ on the formation of a mixture of amorphous $\mathrm{Ag}$ and the dispersed phase of $\mathrm{FeCo}_{3}, a=0,2841 \mathrm{~nm}$, the presence of diffuse maxima on the electron diffraction pattern and a microstructure that did not have the diffraction contrast characteristic of crystal structures (Fig. 3). However, the CRS estimates for this film showed that they are about $3 \mathrm{~nm}$, which indicates the nanocrystalline nature of its microstructure. With increasing silver content and a decrease cobalt content (Co- $24 \% \mathrm{Fe}-$ $14 \% \mathrm{Ag}$ and $\mathrm{Co}-24 \% \mathrm{Fe}-20 \% \mathrm{Ag}$ ), a dispersed $\mathrm{Ag}$ solid solution and an FeCo phase with an ordered bcc structure were observed in the films.

In the films $\mathrm{Fe}-16.5 \% \mathrm{Ag}-4.5 \% \mathrm{Bi}$ and $\mathrm{Fe}-21 \% \mathrm{Ag}-4 \% \mathrm{Bi}$ nanocrystalline phase is formed. This is evidenced by the presence at small angles of X-ray diffraction patterns and electron diffraction patterns of only one diffuse line.

The effective size of the coherent scattering regions is $\mathrm{L}=5-12 \mathrm{~nm}$. The fixed interplanar spacing makes it possible to assume that the short-range ordering in the arrangement of atoms in the microcrystalline phase is close to the bcc orientation of atoms on the basis of iron. It can be seen that the addition of immiscible elements ( $\mathrm{Ag}$, $\mathrm{Bi}, \mathrm{Ag}+\mathrm{Bi}$ ) more than 18,21, 23 at.\%, Respectively, leads to the formation of amorphous phase or NCP iron in freshly dusty films with MIPS.

$\mathrm{X}$-ray diffraction investigations of samples cooled from temperatures corresponding to the final stages of conversion showed that their phase composition corresponds to equilibrium diagrams, viz. mixtures of pure metals in binary systems and $(\mathrm{Ag}+\mathrm{FeCo})$ in the Fe-Co-Ag system with lattice constants practically coinciding with tabulated values.

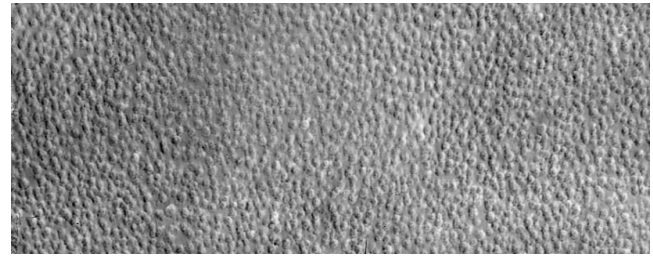

a)

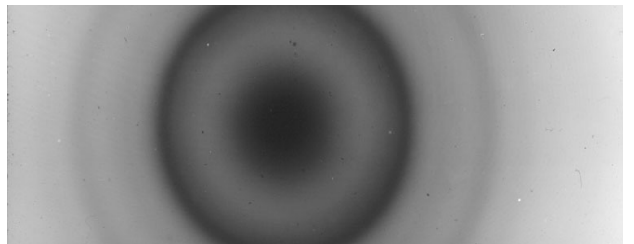

b)

Fig. 3. Structure of the as-deposited $\mathrm{Co}_{65} \mathrm{Fe}_{28} \mathrm{Ag}_{7}$ films (×28000) (a) and the associated diffraction pattern $(b)$

The thermal stability of nonequilibrium structures was estimated from the temperatures of the onset of irreversible changes in the relative electrical resistivity of $R / R_{0}$ films ( $R_{0}$ is the initial resistance) when heated at a constant rate. As can be seen from Fig. 4, when the $\mathrm{Ni}_{64} \mathrm{Ag}_{36}$ film with an amorphous structure is heated, its electrical resistance practically does not change before the crystallization begins (curve 5). Taking into account the fact that alloys with low TCR are of great practical interest, for the films of this system, there were made measurements of the electrical resistivity $\left(\mathrm{R}_{\mathrm{S}}\right)$ and its temperature dependence. As can be seen from Fig. 5, both these characteristics, depending on the composition, vary none monotonically, which indicates the essential role of the structural state. In particular, the formation of an amorphous phase in films leads to a marked increase in the $\mathrm{R}_{\mathrm{S}}$ (up to $\sim 6 \mathrm{Ohm} / \mathrm{sq}$ ) and a sharp decrease in TCR (up to $3 \cdot 10^{-6} \mathrm{~K}^{-1}$ ). The decrease in the electrical resistance on the measured dependences $R(T) / R_{0}$ is due to structural rearrangements. Analysis of the $R(T) / R_{0}$ dependences shows that the temperatures of the onset of irreversible changes are determined primarily by the 48 
chemical composition of the alloy and tend to decrease with increasing concentration of the component with a lower melting point.

The temperatures of the onset of the decomposition of supersaturated solid solutions in the films $\mathrm{Fe}_{88} \mathrm{Ag}_{12}, \mathrm{Fe}_{77} \mathrm{Ag}_{23}$ and $\mathrm{Fe}_{51} \mathrm{Ag}_{49}$ are 680,640 and $580 \mathrm{~K}$, respectively. The thermal stability of Fe-Co-Ag films increases with the increase in silver content from 700 to $650 \mathrm{~K}$, and decreases in films Fe-Bi with increasing bismuth concentration from 5 to 18 at.\% from 685 to $505 \mathrm{~K}$.

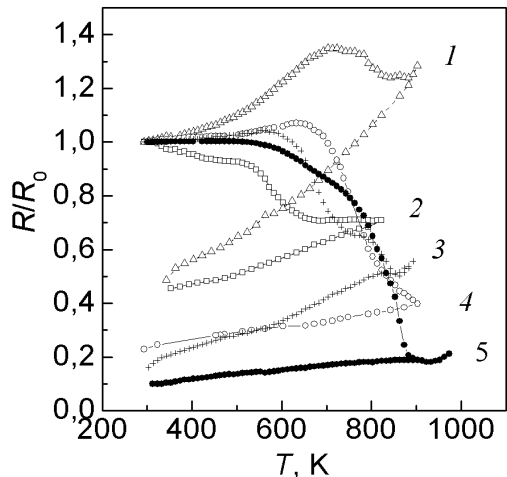

Fig. 4 The change in the relative electrical resistivity of freshly deposited films with heating at a rate of 18 $\mathrm{K} / \mathrm{min}$ : $1-\mathrm{Co}_{65} \mathrm{Fe}_{28} \mathrm{Ag}_{7} ; 2-\mathrm{Fe}_{82} \mathrm{Bi}_{18} ; 3-\mathrm{Fe}_{75} \mathrm{Ag}_{21}-$ $\mathrm{Bi}_{4} 4-\mathrm{Fe}_{77} \mathrm{Ag}_{23} ; 5-\mathrm{Ni}_{64} \mathrm{Ag}_{36}$

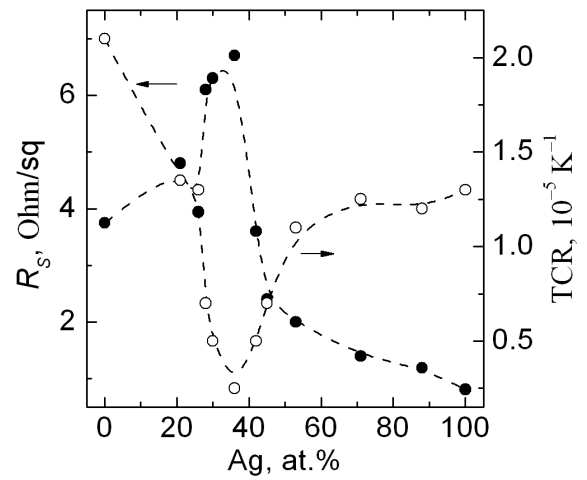

Fig. 5. Compositional dependences of the surface resistance $R_{S}(-\bullet-)$ and temperature coefficient of resistance (-०-) for the asdeposited Ni-Ag films

Investigations have also shown that the temperature coefficients of the electrical resistivity (TCR), depending on the composition and structure of the films, can be both positive and negative (Fig. 4). In Fe-Ag-Bi alloys, an irreversible change in resistance begins at $\sim 570 \mathrm{~K}$, followed by a two-stage transition to an equilibrium state for alloys. The second stage $(\sim 813 \mathrm{~K})$ is associated with the decay of traces of the metastable phase (Table 1). The highest degree of metastability was observed in Fe-16.5\% Ag- $4.5 \% \mathrm{Bi}$ films. Besides, in the alloys of $\mathrm{Fe}-11.5 \% \mathrm{Ag}-4.5 \% \mathrm{Bi}$ and $\mathrm{Fe}-21 \% \mathrm{Ag}-4 \% \mathrm{Bi}$ in the temperature range up to $150 \mathrm{~K}$, small values of the temperature coefficient of resistance $\left(\sim 10^{-5} \mathrm{~K}^{-1}\right)$ are fixed in the region of reversible change $\mathrm{R}_{\mathrm{S}}(\mathrm{T})$.

It should be noted that all decay processes are characterized by low values of the activation energy. The values of this parameter, determined from the well-known Kissinger method (from a shift in the temperature of the onset of structural transformations with a change in the heating rate). For $\mathrm{Fe}_{51} \mathrm{Ag}_{49}, \mathrm{Fe}_{82} \mathrm{Bi}_{18}$ and $\mathrm{Ni}_{79} \mathrm{Ag}_{81}$ alloys the activation energy are $4160 \mathrm{~K}, 4820 \mathrm{~K}$ and $1820 \mathrm{~K}$, respectively. This is approximately an order of magnitude lower than for the decay of nonequilibrium structures in alloys obtained by quenching from the liquid state.This feature is characteristic for films obtained by quenching from the vapor phase [16], and, apparently, due to the increased high contribution of surface diffusion.

In view of the fact that all investigated films contained atoms of ferromagnetic components, it was of interest to estimate their magnetic characteristics, in particular saturation magnetization and the coercive force $\mathrm{H}_{\mathrm{C}}$, which is a structure-dependent quantity. The measurements, the results of which are given in Table 1 showed that the 
sputtered films have a relatively high coercive force, and the field used in the measurements of $0.5 \mathrm{~T}$ was insufficient to reach saturation in some samples.

Table 1.

Results of analysis of demagnetization curves of films Fe-(Ag,Bi)

\begin{tabular}{|c|c|c|c|c|c|}
\hline $\begin{array}{l}\text { The composition (state), } \\
\text { (at\%) }\end{array}$ & $\begin{array}{l}\text { Orientation of the } \\
\text { field and film }\end{array}$ & $\begin{array}{c}H_{C}, \\
\mathbf{k A} / \mathbf{m}\end{array}$ & $\begin{array}{c}M_{r}, \\
M A / m\end{array}$ & $\begin{array}{c}M_{s}, \\
\mathbf{M A} / \mathbf{m}\end{array}$ & $\begin{array}{c}d, \\
\text { nm }\end{array}$ \\
\hline Fe-5\% Bi (h.tr.) & $\|$ & 4 & 0.69 & 1.03 & 140 \\
\hline Fe-5\% Bi(h.tr.) & $\perp$ & 8.5 & 0.23 & 1.03 & 140 \\
\hline Fe-10\% Bi(h.tr.) & $\|$ & 4 & 0.69 & 1.2 & 270 \\
\hline Fe-10\% Bi(in. st.) & $\perp$ & 9 & 0.15 & 1.1 & 270 \\
\hline Fe-10\% Bi(h.tr.) & $\perp$ & 13 & 0.02 & 0.08 & 270 \\
\hline Fe-18\% Bi(in. st.) & & 2.5 & 0.49 & 0.77 & 540 \\
\hline Fe-18\% Bi(h.tr.) & & 2.2 & 0.23 & 0.33 & 540 \\
\hline Fe-12\%Ag(h.tr.) & & 2.4 & 0.23 & 1.3 & 260 \\
\hline Fe-23\%Ag(in. st.) & $\|$ & 1.6 & 0.08 & 1.1 & 260 \\
\hline Fe-23\%Ag(h.tr.) & $\|$ & 11 & 0.21 & 1.1 & 260 \\
\hline Fe-23\%Ag(h.tr.) & $\perp$ & 150 & 0.05 & 0,12 & 260 \\
\hline Fe-49\%Ag(in. st.) & & 0.3 & 0.03 & 0.64 & 440 \\
\hline Fe-49\%Ag(h.tr.) & & 22 & 0.08 & 0.64 & 440 \\
\hline $\mathrm{Co}_{65} \mathrm{Fe}_{28} \mathrm{Ag}_{7}$ (in. st.) & $\|$ & 5.5 & 0.05 & 1,1 & 480 \\
\hline $\mathrm{Co}_{65} \mathrm{Fe}_{28} \mathrm{Ag}_{7}$ (h.tr.) & $\|$ & 12.2 & 0.35 & 1.15 & 480 \\
\hline $\mathrm{Co}_{65} \mathrm{Fe}_{28} \mathrm{Ag}_{7}$ (h.tr.) & $\perp$ & 18.3 & 0.05 & 0,12 & 480 \\
\hline $\mathrm{Co}_{62} \mathrm{Fe}_{24} \mathrm{Ag}_{14}$ (h.tr.) & $\|$ & 12.1 & 0.3 & 1,02 & 540 \\
\hline $\mathrm{Co}_{56} \mathrm{Fe}_{24} \mathrm{Ag}_{20}$ (h.tr.) & $\|$ & 32 & 0.44 & 0,6 & 660 \\
\hline $\mathrm{Co}_{56} \mathrm{Fe}_{24} \mathrm{Ag}_{20}$ (h.tr.) & $\perp$ & 81.2 & 0.05 & 0,3 & 660 \\
\hline $\mathrm{Fe}_{84} \mathrm{Ag}_{11.5} \mathrm{Bi}_{4.5}$ (h.tr.) & $\|$ & 13 & 0.26 & 0.5 & 190 \\
\hline $\mathrm{Fe}_{75} \mathrm{Ag}_{21} \mathrm{Bi}_{4}$ (in.st.) & $\pi$ & 2 & 0.26 & 0.38 & 180 \\
\hline $\mathrm{Fe}_{75} \mathrm{Ag}_{21} \mathrm{Bi}_{4}$ (h.tr.) & $\|$ & 21 & 0.33 & 0.62 & 180 \\
\hline $\mathrm{Fe}_{75} \mathrm{Ag}_{21} \mathrm{Bi}_{4}$ (h.tr.) & $\stackrel{1}{\perp}$ & 16 & 0.05 & 0.44 & 180 \\
\hline $\mathrm{Fe}_{79} \mathrm{Ag}_{16.5} \mathrm{Bi}_{4.5}$ (h.tr.) & $\|$ & 15 & 0.36 & 0.56 & 200 \\
\hline $\mathrm{Fe}_{79} \mathrm{Ag}_{16.5} \mathrm{Bi}_{4.5}$ (h.tr.) & $\perp$ & 26 & 0.05 & 0.36 & 200 \\
\hline Fe (h.tr.) & $\|$ & 0,4 & 1.1 & 1.69 & 380 \\
\hline Bi (in.st.) & $\|$ & 9 & 0.03 & 0.1 & 2900 \\
\hline Bi (in.st.) & $\perp$ & 19 & 0.03 & 0.21 & 2900 \\
\hline
\end{tabular}

Note: $\mathrm{d}$-film thickness; $\mathrm{M}_{\mathrm{r}}$ - remanent magnetization of the film; $\mathrm{M}_{\mathrm{s}}-$ magnetization at $0.5 \mathrm{~T}$; initial state freshly sputtered samples; h.tr. - heat-treated samples; $\|, \perp_{-}$parallel and perpendicular to the field and film positions, respectively;

From the results obtained, it follows that an increase in the concentration of the diamagnetic component in the alloy leads to a decrease in the magnetization, and an exposure for $5 \mathrm{~min}$ at the completion temperatures of the decay - to an increase in the coercive force up to $150 \mathrm{kA} / \mathrm{m}$ in the $\mathrm{Fe}_{77} \mathrm{Ag}_{23}$ film. For $\mathrm{Fe}-23 \% \mathrm{Ag}$ films after heat treatment, hysteresis curves are observed when the external field is directed both parallel and perpendicular to the plane of the film. As is well known, such anisotropy of properties [17] was also observed for $\mathrm{Ag}_{65} \mathrm{Fe}_{35}$ films, while $\mathrm{H}_{\mathrm{C}}$ in the perpendicular film 
reached $\sim 72 \mathrm{kA} / \mathrm{m}$. The obtained high value of the coercive force in Fe-Ag films is comparable with the values obtained in films based on the Fe-Nd-B system, which is the leader in its magnetically rigid characteristics.

The most probable cause of significant magnetic anisotropy (the difference in the values of $\mathrm{H}_{\mathrm{C}}$ measured at different orientations relative to the applied field) consists in the predominant orientation of the nanocrystals formed during quenching, which is enhanced during their growth [4].

From the results shown in Fig. 4-5 and in Table 1, it follows that the variation in the composition and heat treatment regimes lead to a significant change in the electrical and magnetic properties of the sputtered films of systems with a high positive mixing energy, which is important from the point of view of their practical application.

\section{Conclusions}

It is shown that amorphous and nanocrystalline structures are formed as a result of quenching from the vapor state by the method of modernized ion-plasma sputtering of the $\mathrm{Ni}-\mathrm{Ag}, \mathrm{Fe}-\mathrm{Bi}, \mathrm{Fe}-\mathrm{Ag}$, and Fe-Co-Ag systems, characterized by immiscibility of the components in the liquid state. The maximum degree of homogeneity of metastable structures correlates with the value of the mixing energy of the components. In particular, as the mixing energy decreases from 94 to $52 \mathrm{~kJ} / \mathrm{mol}$ in the series of $\mathrm{Fe}-\mathrm{Bi}, \mathrm{Ag}-\mathrm{Fe}, \mathrm{Ag}$ $\mathrm{Co}$, and Ag-Ni systems, the minimum size of nanoscale crystallites decreases from 9 to 3 $\mathrm{nm}$ (in the $\mathrm{Ag}-\mathrm{Fe}-\mathrm{Co}$ ), and in $\mathrm{Ag}-\mathrm{Ni}$ alloys an amorphous phase with dimensions of coherent scattering region of $1.6 \mathrm{~nm}$ is formed.

The established correlation indicates the important role of the thermodynamic factor in the formation of nonequilibrium states in sputtered films and the need to increase the kinetic energy of atoms in the ion-plasma sputtering method to obtain more homogeneous structures. In Bi films and $\mathrm{Fe}-\mathrm{Bi}$ alloys obtained by ion-plasma sputtering, a metastable bcc modification is formed, analogous to the phase formed in pure bismuth at a pressure of $7.75 \mathrm{GPa}$.

It is shown that the electrical and hysteresis magnetic properties of the sputtered films vary widely, depending on the composition and structural state. The compositions and conditions for obtaining films with low $\left(\sim 10^{-5} \mathrm{~K}^{-1}\right)$ values of the temperature coefficient of resistance and high coercive force $(\geq 150 \mathrm{kA} / \mathrm{m})$ are promising for use as thin-film precision resistors and data carriers, respectively.

Thus, the results of structural investigations indicate the high efficiency of the modernized method of ion-plasma sputtering for the production of materials with metastable structures, even in alloys whose components do not mix in the liquid state

\section{References}

1. He, J.H. Amorphous structures in the immisible Ag-Ni system/J.H. He, H.W. Sheng, P.J. Schilling et al. / Phys. Rev. Lett. - 2001. - Vol. 86. - P. 2826 - 2829.

2. Touboltsev, $\mathbf{V}$. Solute-defect interactions in a metastable $\mathrm{Pb}-\mathrm{Ni}$ alloy formed by high-fluence ion implantation/ V. Touboltsev, J. Raisanen, M. Kolodyazhnaya et al. / J.Appl.Phys. - 2002. - Vol. 92, N 2. - P. 895 - 901.

3. Bashev, V.F. Usloviya obrazovaniya metastabil'noy fazy vysokogo davleniya $\mathrm{v}$ zhidkozaka-lennom samarii/V.F. Bashev/ Fizika i tekhnika vysokikh davleniy. 1998. Vol. 8, N 1. P. 93 - 96. (in Russian)

4. Wan, H. Direct evidence of phase separation in as-deposited $\mathrm{Fe}(\mathrm{Co})-\mathrm{Ag}$ films with giant magnetoresistance/H. Wan, A. Tsoukatos, G.C. Hadjipanayis et al. // Phys. Rev. B. - 1994. - Vol. 49, N2. - P.1524 - 1527 
5. Hsu, Jen-Hwa. Long magnetic relaxation time of Fe-Bi spin-glass system/ JenHwa Hsu, J.T. Lee, Ching-Ray Chang, M.T. Lin // Journal of Magnetism and Magnetic Materials. - 2001. - Vol. 226-230. - P.502-504.

6. Zhang, Y.X. The process-controlled magnetic properties in nanostructured $\mathrm{Fe} / \mathrm{Ag}$ composite films/ Y.X. Zhang, S.H. Liou, R.J. DeAngelis et al. / J. Appl. Phys. - 1991. Vol.69, N 8. - P. 5273 - 5275.

7. Bashev, V.F. Elektricheskiye svoystva i struktura W-Ba plenok v svezhenapylennom i ravnovesnom sostoyaniyakh / V.F. Bashev, F.F. Dotsenko, S.I. Ryabtsev / Fizika metallov i materialovedeniye. - 1995. - T. 80, N 1. - P. 117 - 123.

8. Dotsenko, F.F. Emissionnyye svoystva tonkoplenochnykh splavov iz nesmeshivayushchikhsya komponentov / F.F. Dotsenko, V.F. Bashev, S.I. Ryabtsev, A.S. Korchak / Fizika metallov i metallovedeniye. - 2010. - T. 110, № 3. - S. 237 - 242

9. Bashev, V.F. Structure and electrical properties of Ag-W films in metastable states/ V.F. Bashev, F.F. Dotsenko, I.S. Miroshnichenko, V.M. Pasalsky / The Physics of Metals and Metallography. 1992. - Vol. 73, N. P. 152 - 156.

10. Ma, E. Alloys created between immiscible elements / E. Ma / Progress in Materials Science. - 2005. - Vol. 50. - P. 413 - 509

11. Miedema, A.R. Cohesion in alloys fundamentals of a semi-empirical model / A.R. Miedema, P.F. de Chatel, F.R. de Boer / Physica. - 1980. - Vol. 100B. - P. 1 - 28.

12. Dotsenko, F.F. Fizychni peredumovy formuvannya nadnerivnovazhnykh staniv ta otsinka skladu napylenykh splaviv / F.F. Dotsenko, V.F. Bashev / Visnyk Dnipropetrovskoho Universytetu. Fizyka. Radioelektronika. Dnipropetrovsk. DDU. 2001. - Vol. 7. - P. 8 - 17.

13. Grant, U.A. Prigotovleniye amorfnykh splavov s pomoshch'yu ionnoy implantatsii/ U.A. Grant, A. Ali, L.T. Chadderton i dr. / Bystrozakalennyye metally, pod red. B. Kantora. M.:Metallurgiya. 1983. P. $52-57$.

14. Massalski, T.B. Binary Alloy Phase Diagrams-Second edition. 3 vol./ Editor-inChief; H. Okamoto, P. R. Subramanian, L. Kacprzak, Editors. ASM International, Materials Park, Ohio, USA. - 1990 - 3589 p.

15. Properties of elements. Hand-book. 2. nd ed. M.: Metallurgy. - 1976. -600 p. (in Russian)

16. Skott, M. Termicheskaya stabil'nost' i kristallizatsiya metallicheskikh stekol/ M. Skott. / Bystrozakalennyye metally, pod red. B. Kantora. Metallurgiya. 1983. - P. 106 117.

17. Zhang, Z.X. The process-controlled magnetic properties in nanostructured Fe/Ag composite films/ Y.X. Zhang, S.H. Liou, R.J. DeAngelis, K.W. Lee, C.P. Reed, A. Nazareth // J.Appl.Phys. - 1991. - Vol. 69, N8. - P. 5273 - 5275. 